Published in final edited form as:

Drug Resist Updat. 2007 June ; 10(3): 101-108. doi:10.1016/j.drup.2007.04.001.

\title{
The role of galectin-3 in cancer drug resistance
}

\author{
Tomoharu Fukumori $^{\mathrm{a}}$, Hiro-omi Kanayama ${ }^{\mathrm{a}}$, and Avraham Raz ${ }^{\mathrm{b},{ }^{*}}$ \\ aDepartment of Urology, Institute of Health Biosciences, The University of Tokushima Graduate \\ School, Tokushima 770-8503, Japan \\ bTumor Progression and Metastasis Program, Karmanos Cancer Institute, Wayne State \\ University, 110 East Warren Avenue, Detroit, MI 48201, USA
}

\begin{abstract}
The galectins comprise a family of 14 members of $\beta$-galactoside-binding proteins, characterized by their affinity for $\beta$-galactosides and by a conserved sequence in the carbohydrate recognition domain that bind to the carbohydrate portion of cell surface glycoproteins or glycolipids. Galectin-3, a $31 \mathrm{kDa}$ gene product, is a multifunctional oncogenic protein which regulates cell growth, cell adhesion, cell proliferation, angiogenesis, and apoptosis. Recent studies have revealed that galectin-3 demonstrates anti-apoptotic effects which contribute to cell survival in several types of cancer cells. Intracellular galectin-3 in particular, which contains the NWGR anti-death motif of the Bcl-2 family, inhibits cell apoptosis induced by chemotherapeutic agent such as cisplatin and etoposide in some types of cancer cells. We have also reported that nuclear export of phosphorylated galectin-3 regulates its anti-apoptotic activity in response to chemotherapeutic drugs. Here, we will describe the role of galectin-3 as an anti-apoptotic factor in response to chemotherapeutic drugs and will discuss recent data on its molecular mechanism that contribute to drug resistance. We suggest that targeting galectin-3 could improve the efficacy of anticancer drug chemotherapy in several types of cancer.
\end{abstract}

\section{Keywords}

Galectin-3; Apoptosis; Cancer chemotherapy; Drug resistance

\section{Introduction}

The galectins are members of animal lectins which are a family of carbohydrate-binding proteins characterized by their affinity for $\beta$-galactoside and by a conserved sequence of the carbohydrate recognition domain. Fourteen members of galectin family have been identified and classified into three subgroups based on their structure:

a. prototype (galectin-1, -2, -5, -7, -10,-11, -13, and -14);

b. chimera type (galectin-3);

c. tandem repeat type (galectin- $6,-8,-9$, and -12 ).

These multivalent members of the galectin family have been suggested to play different roles in various biological responses such as regulation of cell growth, cell cycle, and apoptosis (Barondes et al., 1994a,b; Sacchettini et al., 2001; Hirabayashi et al., 2002; Liu et al., 2002; Nakahara et al., 2005).

(C) 2007 Published by Elsevier Ltd.

*Corresponding author. Tel.: +1 313833 0960; fax: +1 313831 7518. raza@karmanos.org (A. Raz). 
Galectin-3, a 31-kDa unique chimeric gene product, is an intracellular and extracellular lectin which is presumed to interact with glycoproteins of the cell surface matrix. It consists of three structural domains: (a) a $\mathrm{NH}_{2}$-terminal domain of 12 amino acid that contains a serine phosphorylation site that is important to regulate its cellular signaling; (b) a repeated collagen-like sequence which rich in glycine, proline, and tyrosine; and (c) a $\mathrm{COOH}-$ terminal carbohydrate recognition domain (CRD) consisting of 140 amino acid residues that contains a single CRD (Fig. 1) (Herrmann et al., 1993; Barondes et al., 1994a,b; Gong et al., 1999).

Galectin-3 is expressed widely cancer cells as well as epithelial and immune cells (Pacis et al., 1991, 2000; Lotan et al., 1994; Liu et al., 1995; Schoeppner et al., 1995; Xu et al., 1995; Castronovo et al., 1996; Hsu et al., 1996; Konstantinov et al., 1996; Van den Brule et al., 1996; Takenaka et al., 2004). The expression of galectin-3 in tumor cells is correlated with tumor invasion and metastatic potential of several types of cancer (Irimura et al., 1991, 2000; Lotan et al., 1994; Schoeppner et al., 1995; Xu et al., 1995; Castronovo et al., 1996; Konstantinov et al., 1996; Van den Brule et al., 1996; Takenaka et al., 2004). It has been shown that galectin-3 is multifunctional oncogenic protein and it regulates cell growth, cell adhesion, cell proliferation, angiogenesis, and apoptosis (Barondes et al., 1994a,b; Perillo et al., 1998; Inohara and Raz, 1995; Inohara et al., 1998; Nangia-Makker et al., 2000; Yang and Liu, 2003; Fukumori et al., 2004). In particular, galectin-3, which contains the NWGR anti-death motif of the Bcl-2 family, inhibits cell apoptosis induced by staurosporine, chemotherapeutic agents, such as cis-diamminedichloroplatinum (cisplatin) and etoposide, tumor necrosis factor a (TNF-a), and nitric oxide in several types of cancer cells (Akahani et al., 1997; Kim et al., 1999; Lin et al., 2000; Yoshii et al., 2002; Fukumori et al., 2006). We also reported that nuclear export of phosphorylated galectin-3 regulates its anti-apoptotic activity in response to chemotherapeutic drugs (Takenaka et al., 2004), suggesting that cytoplasmic galectin-3 is responsible for its anti-apoptotic effect.

In this review, we will describe the recent evidence for galectin-3 as an anti-apoptotic factor in response to chemotherapeutic drugs and recent developments in the understanding of the molecular mechanism of galectin-3 in drug resistance. In addition, we will discuss the clinical significance and future prospect of galectin-3 to improve the efficacy of anticancer drug chemotherapy in several types of cancer.

\section{Expression and localization of galectin-3 in cancer cells}

Galectin-3 is expressed broadly in normal cells and many tumor cells and has been shown to be involved in cell growth, cell proliferation, cell differentiation, cell adhesion, angiogenesis, apoptosis, and tumor progression and metastasis mainly through binding to glycoproteins. Clinical evidences have shown that the expression of galectin-3 is associated with the carcinogenesis and malignant potential in melanoma, head and neck, thyroid, gastric, colon, uterine, and renal cancers (Prieto et al., 2006; Pacis et al., 1991, 2000; Lotan et al., 1994; Schoeppner et al., 1995; Xu et al., 1995; Castronovo et al., 1996; Konstantinov et al., 1996; Van den Brule et al., 1996; Takenaka et al., 2004; Kopper and Timer, 2006).

\subsection{Intracellular distribution of galectin-3 in tumor cells}

Interestingly, the intracellular distribution of galectin-3 in cancer cells varies and depends on the type, state, and condition of the cells. Although galectin-3 is predominantly localized in cytoplasm of several types of tumor cells, it has also been detected in the nucleus, suggesting that galectin-3 is a shuttling protein between the nuclear and cytoplasm cellular compartment and accordingly may have multiple functions (Davidson et al., 2002). In general, in tumor cells cytoplasmic galectin-3 has an important role in its anti-apoptotic activity but has an opposite effect when localized in the nucleus (Califice et al., 2004). 
Sanjuan et al. (1997) reported on down-regulation of galectin-3 in colorectal cancer with increased cytoplasmic expression of galectin-3 at more advanced stages. In human prostate cancer, overexpression of galectin-3 in the cytoplasm can promote its anti-apoptotic activity as well as increase cell proliferation, tumor growth, invasion, and angiogenesis while galectin-3 expression in the nucleus decreases cell proliferation (Califice et al., 2004). The cytoplasmic galectin-3 expression also increased during the progression from normal tissue to tongue cancer, while the nuclear expression markedly decreased. The enhanced expression of galectin-3 in the cytoplasm was associated with a decreased disease-free survival of tongue cancer patients (Honjo et al., 2000). Primary and metastatic melanomas also expressed galectin-3 at a significantly higher level than nevi both in cytoplasm and in nuclei. In addition, there was a negative association between survival of patients and lesions with higher levels of cytoplasmic than nuclear galectin-3 expression (Prieto et al., 2006).

We have found that galectin-3 inhibits cisplatin or 5-FUinduced apoptosis through galectin-3 translocation from the nucleus to the cytoplasm in several types of cancer cells (Takenaka et al., 2004; Fukumori et al., 2006). In breast cancer cells, galectin-3 translocates to the perinuclear membrane following a variety of apoptotic stimuli such as cisplatin, staurosporine, or serum withdrawal. Microscopic analysis revealed that galectin-3 is enriched in the mitochondria and prevents mitochondrial membrane damage and cytochrome $c$ release (Yoshii et al., 2002; Yu et al., 2002; Van den Brule et al., 2000). These experimental and clinical data strongly suggest that cytoplasmic galectin-3 expression in cancer cells has an anti-apoptotic function.

\subsection{Intracellular distribution of galectin-3 in normal cells}

Galectin-3 is expressed widely in epithelial and immune cells, such as gastric mucosa, colon mucosa, mammary epithelium, prostate epithelium, monocytes, and macrophages (Lotan et al., 1994; Pacis et al., 1991, 2000; Castronovo et al., 1996; Liu et al., 1995). In the murine fibroblast cell line NIH 3T3 galectin-3 is randomly localized in both the nucleus and cytoplasm compartments. Galectin-3 was observed to be expressed predominantly in the cytoplasm of murine fibroblast NIH $3 \mathrm{~T} 3$ cells after treatment with 5-fluorouracil (5-FU), suggesting that cytoplasmic distribution of galectin-3 in response to a variety of apoptotic stimuli was commonly observed in normal and cancer cells.

\section{Regulation of apoptosis in tumor cells by galectins}

\subsection{Intracellular localization and apoptosis regulation by galectin-3}

As discussed before, it is thought that the intracellular localization of galectin-3 is an important factor in response to several anticancer drugs. For instance, we have shown that BT549 human breast carcinoma cells in which galectin-3 is overexpressed, are more resistant to apoptosis induced by the DNA-cross-linking agent cisplatin, the anthracycline adriamycin, the anti-metabolite 5-FU and the topoisomerase II inhibitor etoposide than BT549 control cells in which galectin-3 is not expressed (Takenaka et al., 2004; Yang et al., 1996; Akahani et al., 1997). Galectin-3 has also been shown to protect cells against apoptosis induced by serum withdrawal, the loss of cell anchorage (anoikis), UVB irradiation, and exposure to other apoptotic stimuli including cycloheximide/TNF- $a$ and genistein which is a natural isoflavonoid compound found to be a inhibitor of protein tyrosine kinases (Akahani et al., 1997; Matarrese et al., 2000a,b; Yoshii et al., 2002; Lin et al., 2000). It was suggested that a Asp-Trp-Gly-Arg (NWGR) motif in the C-terminal domain of galectin-3 was important for resistance to apoptosis, since an amino acid substitution of glycine to alanine in theNWGR motif resulted in loss of resistance to apoptosis induced by cisplatin (Fig. 1) (Yang et al., 1996; Akahani et al., 1997). The NWGR motif in the C-terminal domain of galectin-3 is highly conserved in theBH1domain of the 
Bcl-2 gene family including Bcl-2, Bcl-xL, and Bax (Hanada et al., 1995). This motif is known to be critical for the anti-apoptotic function of the Bcl-2 protein, and also to be essential for the carbohydrate-binding activity of galectins (Yang et al., 1998). Importantly, only galectin-3 has a complete NWGR motif among the galectin family, even though other galectins conserve this domain (Wada et al., 1997; Yang et al., 1996).

Recently we have also found that human prostate cancer cells transfected with galectin-3 are also more resistant to apoptosis induced by cisplatin or etoposide (Fukumori et al., 2006) and that galectin-3 inhibited mitochondrial depolarization and damage after translocation from the nucleus to the cytoplasm in response to cisplatin, resulting in inhibition of cytochrome $c$ release from mitochondria and caspase-3 activation. In addition, overexpression of galectin-3 in the bladder carcinoma cell line J82, conferred resistance to apoptosis induced by engagement of TNF-related apoptosis-inducing ligand (TRAIL). Galectin-3 promoted the activation of the PI3K/Akt pathway in J82 cells, preventing loss of the mitochondrial membrane potential, thereby resulting in less caspase- 9 and -3 activation and suppression of apoptosis (Oka et al., 2005). Thus, cytoplasmic galectin-3 stabilized the mitochondrial membrane potential and inhibited caspase activation.

\subsection{Intracellular localization and apoptosis regulation by other galectins}

The potential anti-apoptotic function of galectins other than galectin-3 has not been extensively investigated. Many studies using recombinant galectins have shown that several members of the galectin family are involved in regulation of apoptosis. In general, exogenously added galectins, including galectin-1, -2, -3, -7, and -9 induce apoptosis of immune cells and cancer cells suggesting a pro-apoptotic function (Perillo et al., 1995, 1997; Sturm et al., 2004; Fukumori et al., 2003; Kuwabara et al., 2002;Wada et al., 1997; Kashio et al., 2003). Also transfection of galectin-7 into keratinocytes made these cells more prone to apoptosis (Bernerd et al., 1999). Galectin-12 has been shown to stimulate apoptosis when it is overexpressed in a fibroblast cell line (Hotta et al., 2001). Thus, extracellular galectins seem to act as pro-apoptotic factors especially for immune cells and intracellular, cytoplasmic galectins - except for galectin-3 - are involved in apoptosis for epithelial cells. In conclusion, the existing evidence clearly indicates that galectin-3 is the only member of the galectin family that is selectively acting as an antiapoptotic factor in cancer cells, suggesting that galectin-3 is a molecular target for improving anticancer drug sensitivity.

\section{The mechanism of galectin-3 in anticancer drug resistance}

Current evidence suggests that the regulation of the anti-apoptotic activity of galectin-3 may result from intracellular effects on the regulation of apoptotic pathways. However, the molecular mechanism by which galectin-3 inhibits apoptosis induced by anticancer drugs remains incompletely understood. The process of the anti-apoptotic action of galectin- 3 has been shown to include: (a) phosphorylation of galectin-3, (b) translocation of galectin-3, (c) regulation of mitochondrial membrane potential, (d) regulation of a cell survival signaling pathway, and (e) regulation of the caspase pathway.

\subsection{Phosphorylation of galectin-3}

Phosphorylation of galectin-3 plays the role of an "on-off" switch for protein-carbohydrate interactions. The phosphorylation status is also critical for the biological functions of galectin-3 such as cell-cycle regulation, anti-apoptotic function, and drug resistance. The major site of phosphorylation is Ser-6 and a minor site is Ser-12, as identified by mass spectrophotometric analysis (Fig. 1) (Huflejt et al., 1993; Mazurek et al., 2000). Phosphorylated galectin-3 has been shown to upregulate the activity of the mitogenactivated protein kinase (MAPK) pathway, which is involved in anti-apoptosis (Takenaka et 
al., 2004). Overexpression of wild-type galectin-3 in BT549 human breast cancer cells inhibits apoptosis induced by such stimuli as anoikis and cisplatin, while substitution of Ser- 6 of galectin- 3 by the non-phosphorylatable alanine inhibits its anti-apoptotic function (Yoshii et al., 2002). Expression of Ser-6 mutants of galectin-3 failed to protect cells from cisplatin-induced cell death and poly-(ADP-ribose) polymerase from degradation when compared with wild-type galectin-3. The non-phosphorylated galectin-3 mutants also failed to protect cells from anoikis with G1 arrest when cells were cultured in suspension. In response to a loss of cell-substrate interactions, only cells expressing wild-type galectin-3 down-regulated cyclin A expression and upregulated cyclin D1 and cyclin-dependent kinase inhibitors, i.e. p21(WAF1/CIP1) and p27(KIP1) (Yoshii et al., 2002). These results demonstrate that galectin-3 phosphorylation is critical for the regulation of its antiapoptotic signaling activity.

\subsection{Translocation of galectin-3}

Recent evidence has shown that translocation of galectin-3 from the nucleus to the cytoplasm and mitochondria during the response to anticancer drugs is necessary for its effect on apoptosis regulation. We have shown that phosphorylated wild-type galectin-3 is exported from the nucleus to the cytoplasm and protects cancer cells from drug-induced apoptosis while non-phosphorylated Ser-6 mutant galectin-3 is neither exported from the nucleus nor protected cancer cells from drug-induced apoptosis (Takenaka et al., 2004). Other investigators have also reported that under certain conditions galectin- 3 is found in the cytoplasm and perinuclear mitochondrial membranes (Yu et al., 2002; Van den Brule et al., 2000), where it is involved in the control of apoptosis possibly through an interaction with the bcl-2 protein (Yang et al., 1996).

The mechanism of translocation of galectin-3 has been revealed by in vitro nuclear import assays. There seemed to be at least two independent nuclear pathways for shuttling galectin-3 into the nucleus: a passive diffusion and an active transport. Galectin- 3 is translocated to the nucleus, in part, via the importin- $\alpha$ and $-\beta$ route and the Arg- 224 amino acid residue of human galectin-3 is essential for its active nuclear translocation and its molecular stability (Fig. 1) (Nakahara et al., 2006). These results may lead to the development of a therapeutic modality aiming at abrogating galectin- 3 translocation and hampering its activity during cancer chemotherapy.

\subsection{Regulation of mitochondrial membrane potential}

Mitochondria are located in the cytoplasm and play a critical role in the control of apoptosis. In general, apoptotic stimuli induce the disruption of electron transport of mitochondria, loss of mitochondrial transmembrane potential, and cytochrome $c$ release, resulting in caspase- 9 and -3 activation (Green, 1998; Thornberry and Lazebnik, 1998; Fukumori et al., 2003; Oliver and Vallette, 2005). Current evidence favors that cytoplasmic galectin-3 localization in breast or prostate cancer cells inhibits the loss of mitochondrial membrane potential, resulting in the inhibition of apoptosis (Matarrese et al., 2000a,b; Yu et al., 2002; Fukumori et al., 2006). As described above, the location of galectin-3 is critical for its activity, since overexpression of galectin-3 in the cytoplasm of human prostate cancer cells can promote its anti-apoptotic activity while overexpression of galectin-3 in the nucleus has the opposite effect (Califice et al., 2004). We have shown that galectin-3 is translocated from the nucleus to the cytoplasm after cisplatin treatment and attenuates the depolarization of the mitochondrial membrane. The latter was examined by confocal microscopy after staining living cells with the cationic dye JC-1, which exhibits potential-dependent accumulation in mitochondria. Mitochondrial depolarization occurring at early stages of apoptosis is detectable in JC-1 stained cells by a decrease in the red/green fluorescence intensity ratio (Fukumori et al., 2006). Our data suggest that cytoplasmic galectin-3 inhibited 
mitochondrial depolarization and damage induced by cisplatin resulting in anticancer drug resistance.

Similar to prostate cancer, it has been also revealed in breast cancer cells by confocal microscopy and biochemical analysis that galectin-3 is enriched in the mitochondria following a variety of apoptotic stimuli and suppresses mitochondrial damage and cytochrome $c$ release (Yu et al., 2002). Furthermore, it has been shown that galectin-3 transfected CEM cells are more resistant to apoptosis induced by $\mathrm{C}_{2}$-ceramide which affects mitochondrial components directly (Garcia-Ruiz et al., 1997; Quillet-Mary et al., 1997; Gudz et al., 1997; Fukumori et al., 2003), suggesting that endogenous galectin-3 blocked $\mathrm{C}_{2}$-ceramide apoptotic signaling on the mitochondria.

\subsection{Regulation of survival signaling pathway}

Galectin-3 has been shown to regulate the expression of several molecules in the survival signaling pathway. Phosphorylated galectin-3 has been shown to increase the activity of the mitogen-activated protein kinase pathway, such as pERK, which is known to be involved in regulation of mitochondrial stability and apoptosis (Takenaka et al., 2004). Galectin-3 also upregulates Akt/PI3K activity (Oka et al., 2005). Akt inhibits apoptosis by blocking Bid cleavage, which is essential for cytochrome $c$ release from the mitochondrial intermembrane space (Datta et al., 1997, 1999). The bladder cancer cell line J82, which overexpresses galectin-3, has a high level of constitutively active Akt and is resistant to TRAIL-induced apoptosis (Oka et al., 2005). Moreover, the blocking of TRAIL-induced apoptosis signals in J82 cells seemed to be mediated by Akt through the inhibition of Bid cleavage, suggesting that galectin-3 protects these cells via the Akt pathway from TRAILinduced apoptosis. In contrast, in a very recent study it was found in the BT549 breast cancer cell line, that phosphorylated galectin-3 promoted TRAIL-induced apoptosis and sensitivity through a non-classical, phosphatase and tension homologue deleted on chromosome 10 (PTEN)-mediated Akt dephosphorylation (Mazurek et al., 2007). The difference with the J82 cell line might be that in J82 cells TRAIL induces mitochondriadependent apoptosis, while in the breast cancer cell line TRAIL triggers a mitochondriaindependent apoptotic pathway (Mazurek et al., 2007).

Bcl-2-associated death protein (Bad) is a member of the Bcl-2 protein family, which plays a critical role in apoptosis. Bad expression and its phosphorylation regulate Bcl-2 expression and the balance between pro-apoptotic (e.g. Bad and Bax) and anti-apoptotic (e.g. Bcl-2 and $\mathrm{Bcl}-\mathrm{XL}$ ) members of the Bcl-2 family and is critical to regulate mitochondria-induced apoptosis (Desagher and Martinou, 2000; Mashima and Tsuruo, 2005). In prostate cancer cells, translocated cytoplasmic galectin-3 after treatment with cisplatin, induced Bad phosphorylation and suppressed Bad expression, resulting in the inhibition of mitochondrial membrane depolarization and apoptosis (Fukumori et al., 2006).

\subsection{Regulation of the caspase pathway}

Caspase-3 is a critical downstream protease in the apoptotic cascade (Enari et al., 1996), which is involved in cell death in response to numerous apoptotic stimuli including Fas ligand or TNF-a complex with its receptor (Hsu et al., 1995; Green, 1998; Mollinedo and Gajate, 2006). For instance, galectin-3 expressing T- or B-cells (such as H9 or SKW6.4) have a lower caspase-3 activation following anti-Fas anti-body than galectin-3-null Jurkat and CEM cells. Interestingly, galectin-3-transfected CEM cells can inhibit caspase-3 activation after treatment with anti-Fas antibody compared with parental CEM cells (Fukumori et al., 2004), suggesting that intracellular galectin-3 can regulate caspase-3 activation. In prostate cancer, intracellular galectin-3 inhibited cytochrome $c$ release from the mitochondria after treatment with cisplatin, and suppressed both active caspase- 3 
expression and activity of caspase-3. In human breast cancer, galectin-3 expression also down-regulates DEVDase (caspase-3 like) activity after treatment with cisplatin (Yu et al., 2002). These results suggest that intracellular galectin-3 may directly affect the mitochondrial integrity, leading to the inhibition of both cytochrome $c$ release from mitochondria and the downstream effector caspase-3.

These data suggest the following model for the mechanism by which galectin-3 can protect cells against pro-apoptotic anticancer drugs (Fig. 2). Phosphorylated galectin-3 translocates from the nuclear to cytoplasmic compartment in response to anticancer drugs, regulates pBad, pAkt, and pERK expression and promotes the stabilization of mitochondrial membrane integrity. Consequently, the stabilization of the mitochondrial membrane suppresses cytochrome $c$ release and subsequent caspase activation, resulting in suppression of apoptosis and resistance to chemotherapeutic agents.

\section{Clinical significance and prospect of galectin-3}

It has been reported that galectin-3 is overexpressed in many human tumors such as thyroid carcinoma, breast carcinoma, gastric carcinoma, colon carcinoma, ovarian carcinoma, prostate carcinoma, melanoma, anaplastic large cell lymphoma as well as in HTLV-1infected T-cells. Moreover, clinical evidence in support of a correlation between galectin-3 expression and malignant potential in some types of tumors such as colon cancer and malignant thyroid tumor has been reported (Pacis et al., 1991; Xu et al., 1995). Importantly, cytoplasmic galectin-3 expression seems to be strongly implicated in an anti-apoptotic function and drug resistance in cancer cells, suggesting that cytoplasmic galectin- 3 is a candidate target protein to suppress anticancer drug resistance. On the other hand, extracellular galectin-3 has been also useful as a diagnostic and prognostic marker since the level of circulating soluble galectin-3 in sera of patients with lung, breast, gastrointestinal, ovarian cancer, melanoma, and Hodgkin's lymphoma was significantly higher than that of healthy subjects and circulating levels of galectin-3 reflect biological aspects of tumor behavior associated with a metastasizing phenotype (Iurisci et al., 2000).

Down-regulation of galectin-3 in the breast cancer cell line MDA-MB-435 by antisense oligonucleotides has been reported to lead to reversion of the transformed phenotype as determined by altered morphology, loss of serum-independent growth, acquisition of growth inhibition properties by cell contact and abrogation of anchorage-independent growth. The blockage of galectin-3 expression led to a significant suppression of tumor growth in nude mice (Honjo et al., 2001). A recent study has shown the superinvasive phenotype exhibited by paclitaxel-selected variants of an in vitro invasive clonal population of MDA-MB-435S cells. This phenotype is indicative of aggressive metastasis-like behavior (Glynn et al., 2004, 2006). Importantly, galectin-3 has been found to be one of the upregulated protein in the superinvasive cells by proteomic analysis (Dowling et al., 2007), suggesting that galectin-3 is involved in anticancer drug resistance. Anticancer drug exposure can result in the conversion of cells from a non-invasive to an invasive phenotype possibly because anticancer drugs can cause mutations in MDA-MB-435 breast carcinoma cells (Glynn et al., 2004). These results provide direct evidence that galectin- 3 expression is necessary for the maintenance of the transformed and drug-resistant phenotype of some types of cancer cells. Concerning prostate cancer, there is no effective treatment for patients with metastasized hormone refractory cancer because these tumor cells are resistant to anticancer drugs, probably due to enhanced resistance to apoptosis. Down-regulation of intracellular galectin- 3 by antisense or siRNA approaches can be a useful strategy to enhance the response to anticancer drugs of specific types of cancer such as prostate and breast cancer. As one of the candidates for the treatment of cancers by application of a galectin-3 inhibitory approach, we have reported a novel therapy using modified citrus pectin (MCP), 
which is competitive inhibitor for natural ligands of galectin-3 (Pienta et al., 1995; NangiaMakker et al., 2002). MCP has been shown to inhibit homotypic aggregation of tumor cells, angiogenesis and tumor cell adhesion to endothelial cells in vitro. Intravenous injection of MCP inhibited experimental lung metastasis of melanoma B16-F1 cells. Oral intake of MCP also inhibited the spontaneous metastasis of rat prostate adenocarcinoma cells and human breast cancer cells. Importantly, recent studies have shown that galectin-3 null mutant mice are relatively healthy (Colnot et al., 1998), suggesting that the galectin-3 inhibitor MCP might be therapeutically valuable without severe side-effects. Taken together, galectin-3 can provide the theoretical foundation for a new therapeutic target for improving chemotherapy of cancers. To clarify a definitive mechanism of galectin-3 in apoptosis, the identification of cancer specific molecules or binding partners associated with galectin-3 and further elucidation of the complex non-classical cellular apoptotic pathways in general, e.g. as in TRAIL-mediated cell death (Mazurek et al., 2007), is required.

\section{Acknowledgments}

We wish to thank Mr. Victor Hogan and Ms. Vivian Powel for manuscript editing.

\section{References}

Akahani S, Nangia-Makker P, Inohara H, Kim HR, Raz A. Galectin-3: a novel anti-apoptotic molecule with a functional BH1 (NWGR) domain of Bcl-2 family. Cancer Res. 1997; 57:5272-5276. [PubMed: 9393748]

Barondes SH, Cooper DN, Gitt MA, Leffler H. Galectins: structure and function of a large family of animal lectins. J. Biol. Chem. 1994a; 269:20807-20810. [PubMed: 8063692]

Barondes SH, Castronovo V, Cooper DN, Cummings RD, Drickamer K, Feizi T, Gitt MA, Hirabayashi J, Hughes C, Kasai K, Leffler H, Liu F, Lotan R, Mercurio AM, Monsigny M, Pillai S, Poirer F, Raz A, Rigby PW, Rini JM, Wang JL. Galectins: a family of animal beta-galactosidebinding lectins (letter). Cell. 1994b; 76:597-598. [PubMed: 8124704]

Bernerd F, Sarasin A, Magnaldo T. Galectin-7 overexpression is associated with the apoptotic process in UVB-induced sunburn keratinocytes. Proc. Natl. Acad. Sci. U.S.A. 1999; 96:11329-11334. [PubMed: 10500176]

Califice S, Castronovo V, Bracke M, Van Den Brule F. Dual activities of galectin-3 in human prostate cancer: tumor suppression of nuclear galectin-3 vs tumor promotion of cytoplasmic galectin-3. Oncogene. 2004; 23:7527-7536. [PubMed: 15326483]

Castronovo V, Van Den Brule FA, Jackers P, Clausse N, Liu FT, Gillet C, Sobel ME. Decreased expression of galectin-3 is associated with progression of human breast cancer. J. Pathol. 1996; 179:43-48. [PubMed: 8691344]

Colnot C, Fowlis D, Ripoche MA, Bouchaert I, Poirier F. Embryonic implantation in galectin 1/ galectin 3 double mutant mice. Dev. Dyn. 1998; 211:306-313. [PubMed: 9566950]

Datta SR, Brunet A, Greenberg ME. Cellular survival: a play in three Akts. Genes Dev. 1999; 13:2905-2927. [PubMed: 10579998]

Datta SR, Dudek H, Tao X, Masters S, Fu H, Gotoh Y, Greenberg ME. Akt phosphorylation of BAD couples survival signals to the cell-intrinsic death machinery. Cell. 1997; 91:231-241. [PubMed: 9346240]

Davidson PJ, Davis MJ, Patterson RJ, Ripoche MA, Poirier F, Wang JL. Shuttling of galectin-3 between the nucleus and cytoplasm. Glycobiology. 2002; 20(12):329-337. [PubMed: 12070075]

Desagher S, Martinou JC. Mitochondria as the central control point of apoptosis. Trends Cell Biol. 2000; 10:369-377. [PubMed: 10932094]

Dowling P, Meleady P, Dowd A, Henry M, Glynn S, Clynes M. Proteomic analysis of isolated membrane fractions from superinvasive cancer cells. Biochim. Biophys. Acta. 2007; 1774:93-101. [PubMed: 17085086]

Enari M, Talanian RV, Wong WW, Nagata S. Sequential activation of ICE-like and CPP32-like proteases during Fas-mediated apoptosis. Nature. 1996; 380:723-726. [PubMed: 8614469] 
Fukumori T, Takenaka Y, Yoshii T, Kim HR, Hogan V, Inohara H, Kagawa S, Raz A. CD29 and CD7 mediate galectin-3-induced type II T-cell apoptosis. Cancer Res. 2003; 63:8302-8311. [PubMed: 14678989]

Fukumori T, Takenaka Y, Oka N, Yoshii T, Hogan V, Inohara H, Kanayama HO, Kim HR, Raz A. Endogenous galectin-3 determines the routing of CD95 apoptotic signaling pathways. Cancer Res. 2004; 64:3376-3379. [PubMed: 15150087]

Fukumori T, Oka N, Takenaka Y, Nangia-Makker P, Elsamman E, Kasai T, Shono M, Kanayama HO, Ellerhorst J, Lotan R, Raz A. Galectin-3 regulates mitochondrial stability and anti-apoptotic function in response to anti-cancer drugs in prostate cancer. Cancer Res. 2006; 66:3114-3119. [PubMed: 16540661]

Garcia-Ruiz C, Colell A, Mari M, Morales A, Fernandez-Checa JC. Direct effect of ceramide on the mitochondrial electron transport chain leads to generation of reactive oxygen species. Role of mitochondrial glutathione. J. Biol. Chem. 1997; 272:11369-11377. [PubMed: 9111045]

Glynn SA, Gammell P, Heenan M, O’Connor R, Liang Y, Keenan J, Clynes M. A new superinvasive in vitro phenotype induced by selection of human breast carcinoma cells with the chemotherapeutic drugs paclitaxel and doxorubicin. Br. J. Cancer. 2004; 91:1800-1807. [PubMed: 15505620]

Glynn SA, Adams A, Gibson B, Cronin D, Harmey JH, Clynes M. Low adhesiveness coupled with high superinvasiveness in vitro predicts the in vivo metastatic potential of a mouse mammary adenocarcinoma cell line. Anticancer Res. 2006; 26:1001-1010. [PubMed: 16619499]

Gong HC, Honjo Y, Nangia-Makker P, Hogan V, Mazurak N, Bresalier RS, Raz A. The NH2 terminus of galectin-3 governs cellular compartmentalization and functions in cancer cells. Cancer Res. 1999; 59:6239-6245. [PubMed: 10626818]

Green DR. Apoptotic pathways: the roads to ruin. Cell. 1998; 94:695-698. [PubMed: 9753316]

Gudz TI, Tserng KY, Hoppel CL. Direct inhibition of mitochondrial respiratory chain complex III by cell-permeable ceramide. J. Biol. Chem. 1997; 272:24154-24158. [PubMed: 9305864]

Hanada M, Aimé-Sempé C, Sato T, Reed JC. Structure-function analysis of Bcl-2 protein. Identification of conserved domains important for homodimerization with Bcl-2 and heterodimerization with Bax. J. Biol. Chem. 1995; 270:11962-11969. [PubMed: 7744846]

Herrmann J, Turck CW, Atchison RE, Huflejt ME, Poulter L, Gitt MA, Burlingame AL, Barondes SH, Leffler H. Primary structure of the soluble lactose binding lectin L-29 from rat and dog and interaction of its non-collagenous praline-, glycine-, tyrosine-rich sequence with bacteria and tissue collagenase. J. Biol. Chem. 1993; 268:26704-26711. [PubMed: 8253805]

Hirabayashi J, Hashidate T, Arata Y, Nishi N, Nakamura T, Hirashima M, Urashima T, Oka T, Futai M, Muller WE, Yagi F, Kasai K. Oligosaccharide specificity of galectins: a search by frontal affinity chromatography. Biochim. Biophys. Acta. 2002; 1572:232-254. [PubMed: 12223272]

Honjo Y, Nangia-Makker P, Inohara H, Raz A. Down-regulation of galectin-3 suppresses tumorigenicity of human breast carcinoma cells. Clin. Cancer Res. 2001; 7:661-668. [PubMed: 11297262]

Honjo Y, Inohara H, Akahani S, Yoshii T, Takanaka Y, Yoshida J, Hattori K, Tomiyama Y, Raz A, Kubo T. Expression of cytoplasmic galectin-3 as a prognostic marker in tongue carcinoma. Clin. Cancer Res. 2000; 6:4635-4640. [PubMed: 11156213]

Hotta K, Funahashi T, Matsukawa Y, Takahashi M, Nishizawa H, Kishida K, Matsuda M, Kuriyama H, Kihara S, Nakamura T, Tochino Y, Bodkin NL, Hansen BC, Matsuzawa Y. Galectin-12, an adipose-expressed galectin-like molecule possessing apoptosis-inducing activity. J. Biol. Chem. 2001; 276:34089-34097. [PubMed: 11435439]

Hsu DK, Hammes SR, Kuwabara I, Greene WC, Liu FT. Human T lymphotropic virus-I infection of human T lymphocytes induces expression of the beta-galactoside-binding lectin, galectin-3. Am. J. Pathol. 1996; 148:1661-1670. [PubMed: 8623933]

Hsu H, Xiong J, Goeddel DV. The TNF receptor 1-associated protein TRADD signals cell death and NF-kappa B activation. Cell. 1995; 81:495-504. [PubMed: 7758105]

Huflejt ME, Turck CW, Lindstedt R, Barondes SH, Leffler H. L-29, a soluble lactose-binding lectin, is phosphorylated on serine 6 and serine 12 in vivo and by casein kinase I. J. Biol. Chem. 1993; 268:26712-26718. [PubMed: 8253806] 
Inohara H, Raz A. Functional evidence that cell surface galectin-3 mediate homotypic cell adhesion. Cancer Res. 1995; 55:3267-3271. [PubMed: 7542167]

Inohara H, Akahani S, Raz A. Galectin-3 stimulates cell proliferation. Exp. Cell. Res. 1998; 245:294302. [PubMed: 9851870]

Irimura T, Matsushita Y, Sutton RC, Carralero D, Ohannesian DW, Cleary KR, Ota DM, Nicolson GL, Lotan R. Increased content of an endogenous lactose-binding lectin in human colorectal carcinoma progressed to metastatic stages. Cancer Res. 1991; 51:387-393. [PubMed: 1988099]

Iurisci I, Tinari N, Natoli C, Angelucci D, Cianchetti E, Iacobelli S. Concentrations of galectin-3 in the sera of normal controls and cancer patients. Clin. Cancer Res. 2000; 6:1389-1393. [PubMed: 10778968]

Kashio Y, Nakamura K, Abedin MJ, Seki M, Nishi N, Yoshida N, Nakamura T, Hirashima M. Galectin-9 induces apoptosis through the calcium-calpain-caspase-1 pathway. J. Immunol. 2003; 170:3631-3636. [PubMed: 12646627]

Kim HR, Lin HM, Biliran H, Raz A. Cell cycle arrest and inhibition of anoikis by galectin-3 in human breast epithelial cells. Cancer Res. 1999; 59:4148-4154. [PubMed: 10463621]

Konstantinov KN, Robbins BA, Liu FT. Galectin-3, a betagalactoside-binding animal lectin, is a marker of anaplastic large-cell lymphoma. Am. J. Pathol. 1996; 148:25-30. [PubMed: 8546213]

Kopper L, Timer J. Genomics of renal cell cancer—does it provide breakthrough? Pathol. Oncol. Res. 2006; 12:5-11. [PubMed: 16554910]

Kuwabara I, Kuwabara Y, Yang RY, Schuler M, Green DR, Zuraw BL, Hsu DK, Liu FT. Galectin-7 (PIG1) exhibits pro-apoptotic function through JNK activation and mitochondrial cytochrome $c$ release. J. Biol. Chem. 2002; 277:3487-3497. [PubMed: 11706006]

Lin HM, Moon BK, Yu F, Kim HR. Galectin-3 mediates genistein-induced G(2)/M arrest and inhibits apoptosis. Carcinogenesis. 2000; 21:1941-1945. [PubMed: 11062152]

Liu FT, Hsu DK, Zuberi RI, Kuwabaraz I, Chi EY, Henderson WR Jr. Expression and function of galectin-3, a beta-galactosidebinding lectin, in human monocytes and macrophages. Am. J. Pathol. 1995; 147:1016-1028. [PubMed: 7573347]

Liu FT, Patterson RJ, Wang JL. Intracellular functions of galectins. Biochim. Biophys. Acta. 2002; 1572:263-273. [PubMed: 12223274]

Lotan R, Ito H, Yasui W, Yokozaki H, Lotan D, Tahara E. Expression of a 31-kDa lactoside-binding lectin in normal human gastric mucosa and in primary and metastatic gastric carcinomas. Int. J. Cancer. 1994; 56:474-480. [PubMed: 8112883]

Mashima T, Tsuruo T. Defects of the apoptotic pathway as therapeutic target against cancer. Drug Resist. Updates. 2005; 8:339-343.

Matarrese P, Tinari N, Semeraro ML, Natoli C, Iacobelli S, Malorni W. Galectin-3 overexpression protects from cell damage and death by influencing mitochondrial homeostasis. FEBS Lett. 2000a; 473:311-315. [PubMed: 10818231]

Matarrese P, Fusco O, Tinari N, Natoli C, Liu FT, Semeraro ML, Malorni W, Iacobelli S. Galectin-3 overexpression protects from apoptosis by improving cell adhesion properties. Int. J. Cancer. 2000b; 85:545-554. [PubMed: 10699929]

Mazurek N, Conklin J, Byrd JC, Raz A, Bresalier RS. Phosphorylation of the beta-galactoside-binding protein galectin-3 modulates binding to its ligands. J. Biol. Chem. 2000; 275:36311-36315. [PubMed: 10961987]

Mazurek N, Sun Y-J, Liu K-F, Gilcrease MZ, Schober W, Nangia-Makker P, Raz A, Bresalier RS. Phosphorylated galectin-3 mediates tumor necrosis factor related apoptosis-inducing ligand (TRAIL) signaling by regulating PTEN in human breast carcinoma cells. J. Biol. Chem. 2007

Mollinedo F, Gajate C. Fas/CD95 death receptor and lipid rafts: new targets for apoptosis-directed cancer therapy. Drug Resist. Updates. 2006; 9:51-73.

Nakahara S, Oka N, Raz A. On the role of galectin-3 in cancer apoptosis. Apoptosis. 2005; 10:267275. [PubMed: 15843888]

Nakahara S, Oka N, Wang Y, Hogan V, Inohara H, Raz A. Characterization of the nuclear import pathways of galectin-3. Cancer Res. 2006; 66:9995-10006. [PubMed: 17047062] 
Nangia-Makker P, Honjo Y, Sarvis R, Akahani S, Hogan V, Pienta KJ, Raz A. Galectin-3 induces endothelial cell morphogenesis and angiogenesis. Am. J. Pathol. 2000; 156:899-909. [PubMed: 10702407]

Nangia-Makker P, Hogan V, Honjo Y, Baccarini S, Tait L, Bresalier R, Raz A. Inhibition of human cancer cell growth and metastasis in nude mice by oral intake of modified citrus pectin. J. Natl. Cancer Inst. 2002; 94:1854-1862. [PubMed: 12488479]

Oka N, Nakahara S, Takenaka Y, Fukumori T, Hogan V, Kanayama HO, Yanagawa T, Raz A. Galectin-3 inhibits tumor necrosis factor-related apoptosis-inducing ligand-induced apoptosis by activating Akt in human bladder carcinoma cells. Cancer Res. 2005; 65:7546-7553. [PubMed: 16140916]

Oliver L, Vallette FM. The role of caspases in cell death and differentiation. Drug Resist. Updates. 2005; 8:163-170.

Pacis RA, Pilat MJ, Pienta KJ, Wojno K, Raz A, Hogan V, Cooper CR. Decreased galectin-3 expression in prostate cancer. Prostate. 2000; 44:118-123. [PubMed: 10881021]

Perillo NL, Pace KE, Seilhamer JJ, Baum LG. Apoptosis of T cells mediated by galectin-1. Nature. 1995; 378:736-739. [PubMed: 7501023]

Perillo NL, Uittenbogaart C, Nguyen J, Baum LG. Galectin- 1, an endogenous lectin produced by thymic epithelial cells, induces apoptosis of human thymocytes. J. Exp. Med. 1997; 185:18511858. [PubMed: 9151710]

Perillo NL, Marcus ME, Baum LG. Galectins: versatile modulators of cell adhesion, cell proliferation, and cell death. J. Mol. Med. 1998; 76:402-412. [PubMed: 9625297]

Pienta KJ, Naik H, Akhtar A, Yamazaki K, Replogle TS, Lehr J, Donat TL, Tait L, Hogan V, Raz A. Inhibition of spontaneous metastasis in a rat prostate cancer model by oral administration of modified citrus pectin. J. Natl. Cancer Inst. 1995; 87:348-353. [PubMed: 7853416]

Prieto VG, Mourad-Zeidan AA, Melnikova V, Johnson MM, Lopez A, Diwan AH, Lazar AJ, Shen SS, Zhang PS, Reed JA, Gershenwald JE, Raz A, Bar-Eli M. Galectin-3 expression is associated with tumor progression and pattern of sun exposure in melanoma. Clin. Cancer Res. 2006; 12:67096715. [PubMed: 17121890]

Quillet-Mary A, Jaffrezou JP, Mansat V, Bordier C, Naval J, Laurent G. Implication of mitochondrial hydrogen peroxide generation in ceramide-induced apoptosis. J. Biol. Chem. 1997; 272:2138821395. [PubMed: 9261153]

Sacchettini JC, Baum LG, Brewer CF. Multivalent protein-carbohydrate interactions. A new paradigm for supermolecular assembly and signal transduction. Biochemistry. 2001; 40:3009-3015. [PubMed: 11258914]

Sanjuan X, Fernandez PL, Castells A, Castronovo V, Van den Brule F, Liu FT, Cardesa A, Campo E. Differential expression of galectin 3 and galectin 1 in colorectal cancer progression. Gastroenterology. 1997; 113:1906-1915. [PubMed: 9394730]

Schoeppner HL, Raz A, Ho SB, Bresalier RS. Expression of an endogenous galactose-binding lectin correlates with neoplastic progression in the colon. Cancer. 1995; 75:2818-2826. [PubMed: 7773932]

Sturm A, Lensch M, Andre S, Kaltner H, Wiedenmann B, Rosewicz S, Dignass AU, Gabius HJ. Human galectin-2: novel inducer of T cell apoptosis with distinct profile of caspase activation. J. Immunol. 2004; 173:3825-3837. [PubMed: 15356130]

Takenaka Y, Fukumori T, Yoshii T, Oka N, Inohara H, Kim HR, Bresalier RS, Raz A. Nuclear export of phosphorylated galectin-3 regulates its antiapoptotic activity in response to chemotherapeutic drugs. Mol. Cell. Biol. 2004; 24:4395-4406. [PubMed: 15121858]

Thornberry NA, Lazebnik Y. Caspases: enemies within. Science. 1998; 281:1312-1316. [PubMed: 9721091]

Van den Brule FA, Buicu C, Berchuck A, Bast RC, Deprez M, Liu FT, Cooper DN, Pieters C, Sobel ME, Castronovo V. Expression of the 67-kD laminin receptor, galectin-1, and galectin-3 in advanced human uterine adenocarcinoma. Hum. Pathol. 1996; 27:1185-1191. [PubMed: 8912829]

Van den Brule FA, Waltregny D, Liu FT, Castronovo V. Alteration of the cytoplasmic/nuclear expression pattern of galectin-3 correlates with prostate carcinoma progression. Int. J. Cancer. 2000; 89:361-367. [PubMed: 10956411] 
Wada J, Ota K, Kumar A, Wallner EI, Kanwar YS. Developmental regulation, expression, and apoptotic potential of galectin-9, a beta-galactoside binding lectin. J. Clin. Invest. 1997; 99:24522461. [PubMed: 9153289]

Xu XC, el-Naggar AK, Lotan R. Differential expression of galectin-1 and galectin-3 in thyroid tumors. Potential diagnostic implications. Am. J. Pathol. 1995; 147:815-822. [PubMed: 7677193]

Yang RY, Hsu DK, Liu FT. Expression of galectin-3 modulates Tcell growth and apoptosis. Proc. Natl. Acad. Sci. U.S.A. 1996; 93:6737-6742. [PubMed: 8692888]

Yang RY, Hill PN, Hsu DK, Liu FT. Role of the carboxyl-terminal lectin domain in self-association of galectin-3. Biochemistry. 1998; 37:4086-4092. [PubMed: 9521730]

Yang RY, Liu FT. Galectins in cell growth and apoptosis. Cell. Mol. Life Sci. 2003; 60:267-276. [PubMed: 12678492]

Yoshii T, Fukumori T, Honjo Y, Inohara H, Kim HR, Raz A. Galectin-3 phosphorylation is required for its anti-apoptotic function and cell cycle arrest. J. Biol. Chem. 2002; 277:6852-6857. [PubMed: 11724777]

Yu F, Finley RL Jr, Raz A, Kim HR. Galectin-3 translocates to the perinuclear membranes and inhibits cytochrome $c$ release from the mitochondria. A role for synexin in galectin-3 translocation. J. Biol. Chem. 2002; 277:15819-15827. [PubMed: 11839755] 


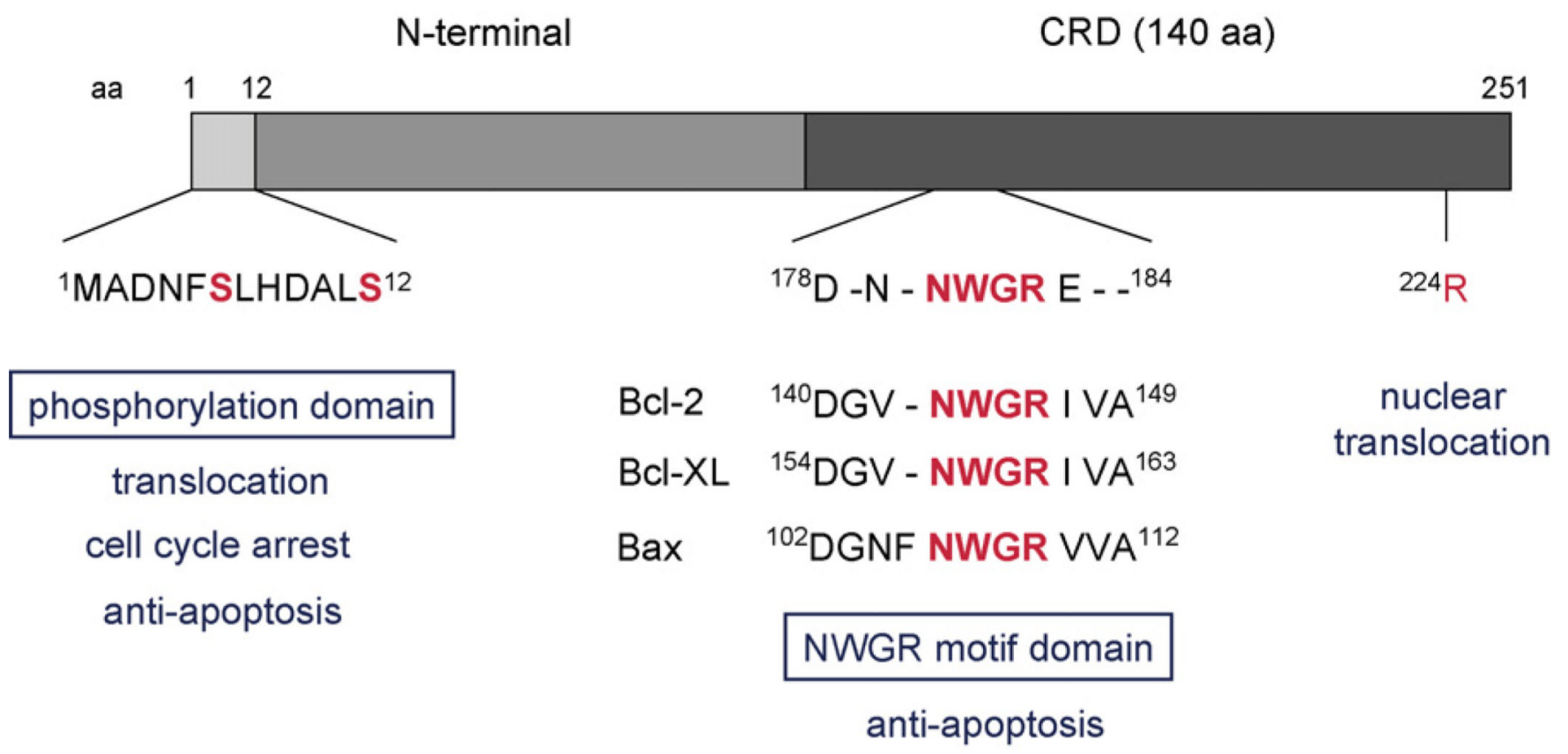

Fig. 1.

Structure and functional domain of galectin-3. Galectin-3 consists of three structural domains: (a) a $\mathrm{NH}_{2}$-terminal domain of 12 amino acid that contains a serine phosphorylation site; (b) a repeated collagen-like sequence rich in glycine, proline, and tyrosine; and (c) a $\mathrm{COOH}$-terminal carbohydrate recognition domain (CRD) consisting 140 amino acid residues. The $\mathrm{C}$-terminal domain includes the NWGR motif which is highly conserved in the $\mathrm{BH} 1$ domain of the Bcl-2 gene family including Bcl-2, Bcl-xL, and Bax. 


\section{Mitochondrial stability}

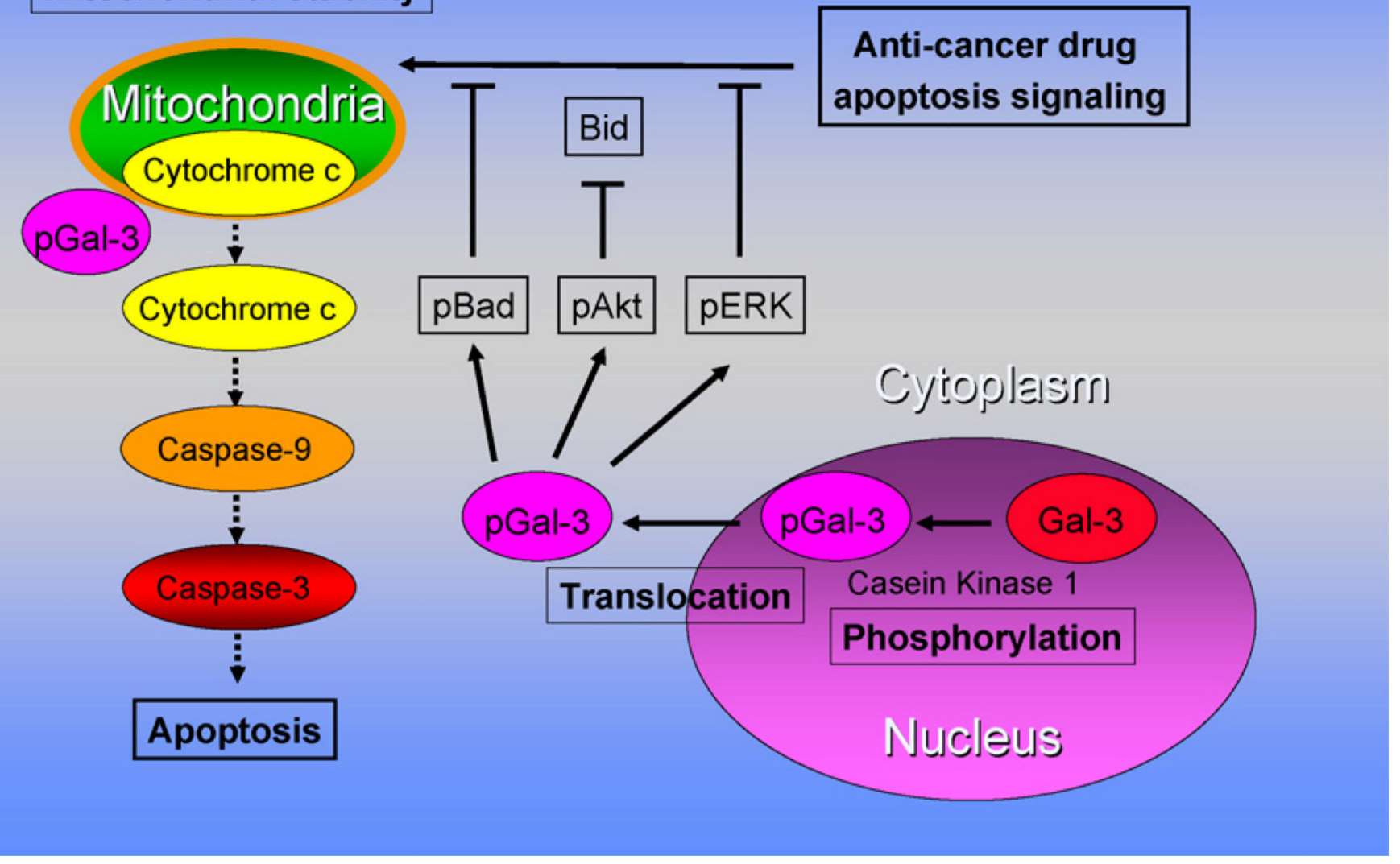

Fig. 2.

Model for the regulation of apoptosis signaling pathways induced by anticancer drugs in galectin-3 expressing cells. Anticancer drugs can induce DNA damage, which causes phosphorylated galectin-3 to translocate from the nucleus to cytoplasm and regulates phosphorylation of Bad, Akt, and ERK resulting in stabilization of mitochondrial membrane integrity. The stabilization of the mitochondrial membrane prevents cytochrome $c$ release and subsequent caspase activation, resulting in suppression of apoptosis and caused anticancer drug resistance. 